\title{
ZFX expression is connected with improved survival in patients with breast cancer
}

Kristian Mcarthur ${ }^{1}$, Gideon Carney ${ }^{1}$, Duncan Bush ${ }^{1}$, Scarlet Sellers ${ }^{1}$, Roan Carpenter ${ }^{1}$, James $\mathrm{K}^{1}$, Maira Hewitt ${ }^{1}$, and Alistair Molloy ${ }^{1}$

${ }^{1}$ Bio-Tech Research and Development Institute, UWI

June 14, 2021

\section{Hosted file}

ZFX expression is connected with improved survival in patients with breast cancer (1).pdf available at https://authorea.com/users/419475/articles/526192-zfx-expression-is-connectedwith-improved-survival-in-patients-with-breast-cancer 